\title{
Active power filters - Recent advances
}

\author{
NED MOHAN and GIRISH R KAMATH \\ Dept. of Electrical \& Computer Engineering, 200, Union St. S.E., University \\ of Minnesota, Minneapolis, MN 55455, USA \\ e-mail: [mohan,gkamath] @ece.umn.edu
}

\begin{abstract}
Power electronic loads inject harmonic currents into the utility causing overheating of power transformers and neutral wires, the power system, unpredictable performance of protection systems etc. In addition, electric resonances in such loads can also cause other undesirable phenomena like voltage fluctuations, radio frequency interference (RFI) etc. To mitigate these undesirable effects, a new class of power electronics equipment (Active Filters) is being considered. A review of present-day solutions in the area of active filters is conducted in this paper. Finally, this paper discusses the trends in the design of active filters and the factors influencing them.
\end{abstract}

Keywords. Active filters; harmonics; multi-level inverter; series-connection; hybrid filters.

\section{Introduction}

In the past few decades, there has been an increase in the use of electric power throughout the world. This increase has been accompanied by the use of equipment in our day to day life which has shown an increasing amount of sophistication and an appetite for good quality electric power. The past few years has also witnessed the occurrence of a number of mishaps like distribution transformers catching fire, blackouts etc. Such incidents are affecting an increasing number of consumers as the use of electric power becomes more widespread. On investigating these accidents, it was found that one of the causes of these occurrences was electric power "pollution". This is generated by the use of modern appliances and equipment connected to the grid. Typical examples at the residential level include computers, colour televisions, fluorescent ballasts etc. At the industrial level, high power Adjustable Speed Drives (ASDs) and arc furnace loads are typical examples of power polluting loads. These loads are used extensively in steel rolling mills, chemical process industries etc.

Common undesirable characteristics of all these loads are the following.

(1) They draw non-sinusoidal current from the utility, and

(2) distort the utility voltage waveforms. 


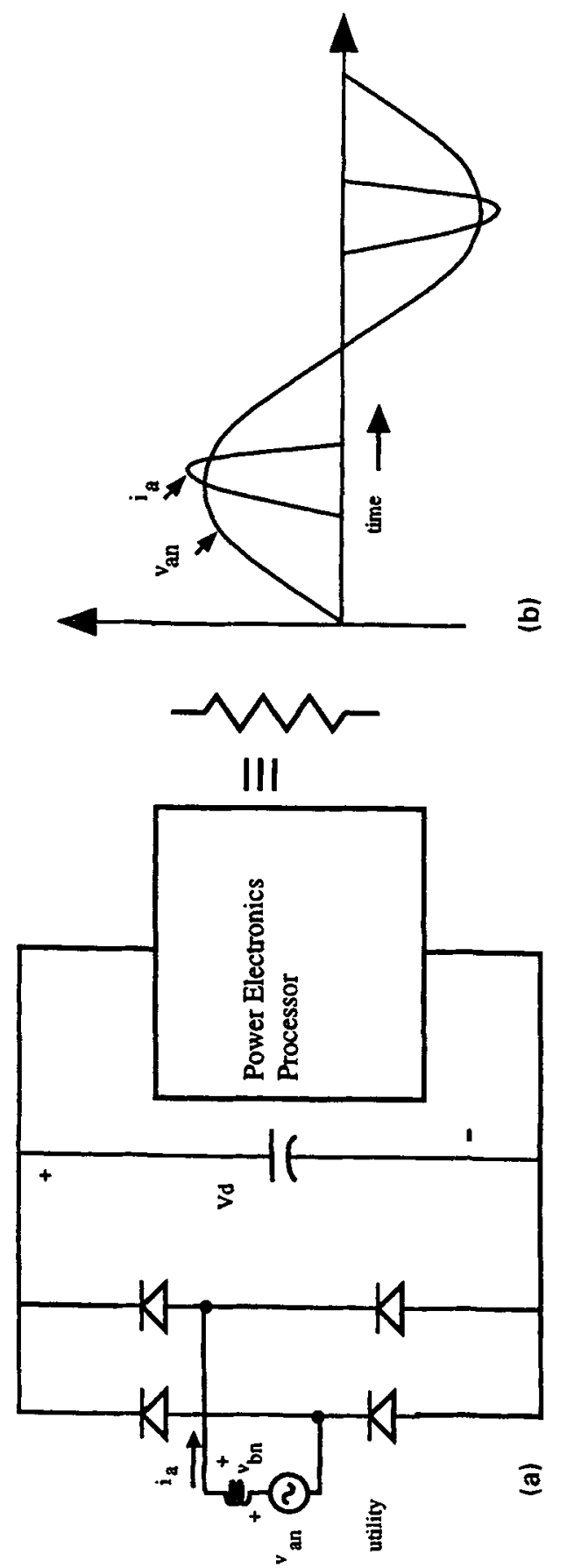


Table 1. Details of harmonic currents drawn by the load of figure 1 .

\begin{tabular}{lc}
\hline Harmonic number & $I_{h} / I_{1}$ (in per unit) \\
\hline 3 & 0.77 \\
5 & 0.42 \\
7 & 0.15 \\
9 & 0.08 \\
\hline
\end{tabular}

From the point of view of studying the effect that such loads have on the utility, it is possible to represent any of the above mentioned examples in terms of the schematic diagram shown in figure 1a which consists of a diode bridge rectifier and a resistor.

In this diagram, the power electronics processor is represented as an equivalent resistor. The current drawn by the load from the utility is shown in figure $1 \mathrm{~b}$. The voltage $v_{b n}$ at the point of common coupling (PCC), shown in figure $1 \mathrm{c}$, is distorted due to the nature of the current drawn by the load. Thus any other consumer who is connected across points $b-n$ would have to face this distorted voltage. The current drawn by the load has a dominant third harmonic component as shown in table 1 which contains a table containing details of the current harmonics. The usage of such loads can lead to overheating of power transformers and neutral wires, electric resonances in the power system, unpredictable performance of protection systems etc. In addition, such loads can also cause other undesirable phenomena like voltage fluctuations, flicker, sags, radio frequency interference (RFI) etc. (Redl et al 1997).

In order to address this issue, certain institutions like the IEEE in the US and IEC (followed in Europe) have established guidelines which set limits on the amount of distortion current that the load can inject into the utility. However, there is a difference in philosophy in the framing of guidelines between the two institutions.

The revision of IEEE-519 guidelines suggested by Duffey \& Stratford (1988) became official in 1992. It takes into account the relative strength of the utility system and sets limits on the amount of harmonics (as a percentage of the fundamental current) that a user can inject at the Point of Common Coupling (PCC). In the case of the IEC-555 standard which was issued in the early 1980s to suggest guidelines for single-phase applications, the emphasis is on limiting the absolute amount of harmonics that is generated at the equipment level. The other major difference is that IEC standards have been enforced into law while IEEE 519-1992 guidelines are still recommendations.

\section{Active filtering and current waveshaping techniques}

In order to address the issue of harmonic current injection, there are two options.

(1) Incorporate current waveshaping circuits within the equipment so that they draw sinusoidal line currents.

(2) Install filters to "clean up" the distorted current waveforms drawn by these loads.

By incorporating power factor correction circuitry into the equipment, active filtering becomes unnecessary. This approach is followed for single-phase applications but may 


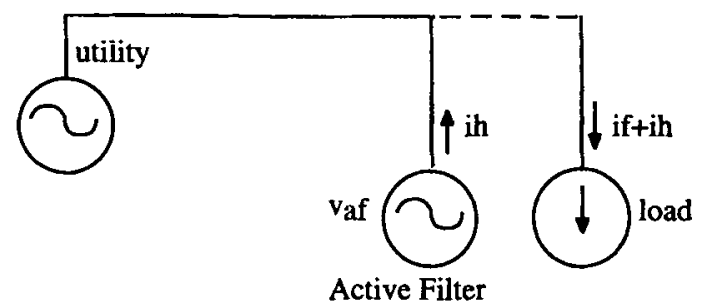

Figure 2. Single line diagram for active filter acting as a harmonic current source.

not be the most cost-effective option, especially at medium to high power level (greater than $10 \mathrm{~kW}$ ).

In such cases it may be more economical to follow the second approach by installing an active filter unit at the plant level in order to solve the problem.

(1) Current waveshaping techniques: IEC standards limit the current harmonics that are generated by single-phase electrical appliances. This encourages the approach where one inserts a power electronics block between such a load and the utility to ensure that it (the utility) is insulated from the effects of the nonlinear load, i.e. the diode bridge rectifier of figure 1a is replaced by a "utility friendly" block which draws sinusoidal current from the mains at unity power factor to maximize efficiency. It then generates the required DC voltage at which the power electronic processor operates.

(2) Active filtering techniques: IEEE 519-1992 recommendations limit the injection of current harmonics by a user at the Point of Common Coupling (PCC). For example, the IEEE 519-1992 recommends a limit of 5\% in weak systems on the Total Harmonic Distortion (THD) in the current at the Point of Common Coupling. The total harmonic distortion (THD) in the current $i_{s}$ drawn from the utility is the ratio of the $r m s$ value of its distortion component to the $r m s$ value of its fundamental-frequency component. It is given as,

$$
\% \text { THD }=\left[\left(\sum_{h=2}^{\infty} I_{h}^{2}\right)\right]^{1 / 2} / I_{1} \times 100
$$

where

$I_{h}=r m s$ value of the current at harmonic order $h$,

$I_{1}=r m s$ value of the fundamental-frequency current component.

In this case, the user is free to use any equipment in his premises which are not necessarily utility "friendly" as long as he uses external harmonic current reduction techniques to meet the guidelines specified. Active filters fall in this category. They are harmonic current sources which are used in conjunction with the utility to provide the required harmonic current demand of the load. Figure 2 shows the single line diagram of an active filter acting as a harmonic current source. In this figure, the active filter provides the harmonic current $i_{h}$ which is demanded by the load. 


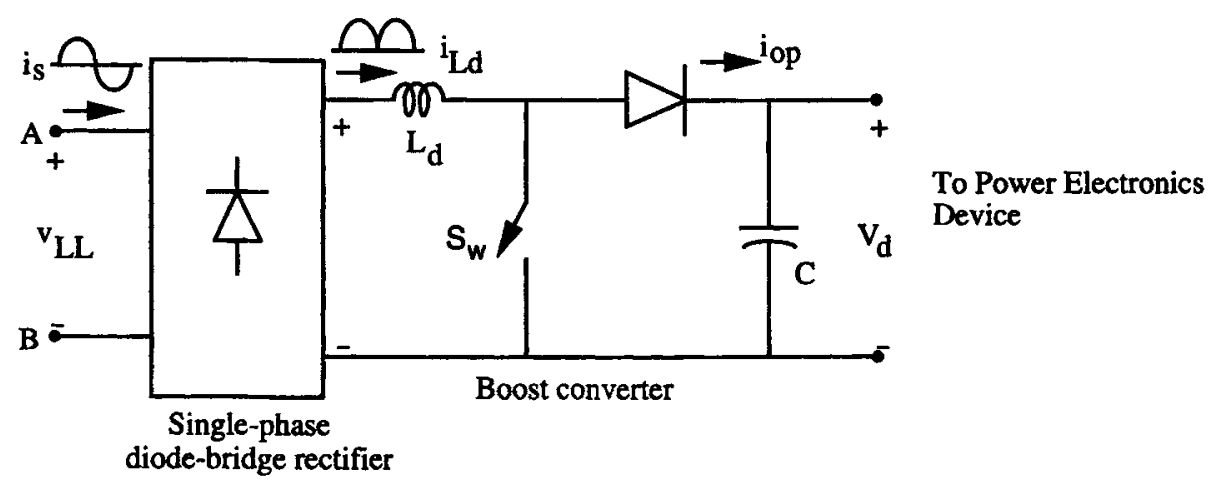

Figure 3. Current waveshaping technique for single-phase applications.

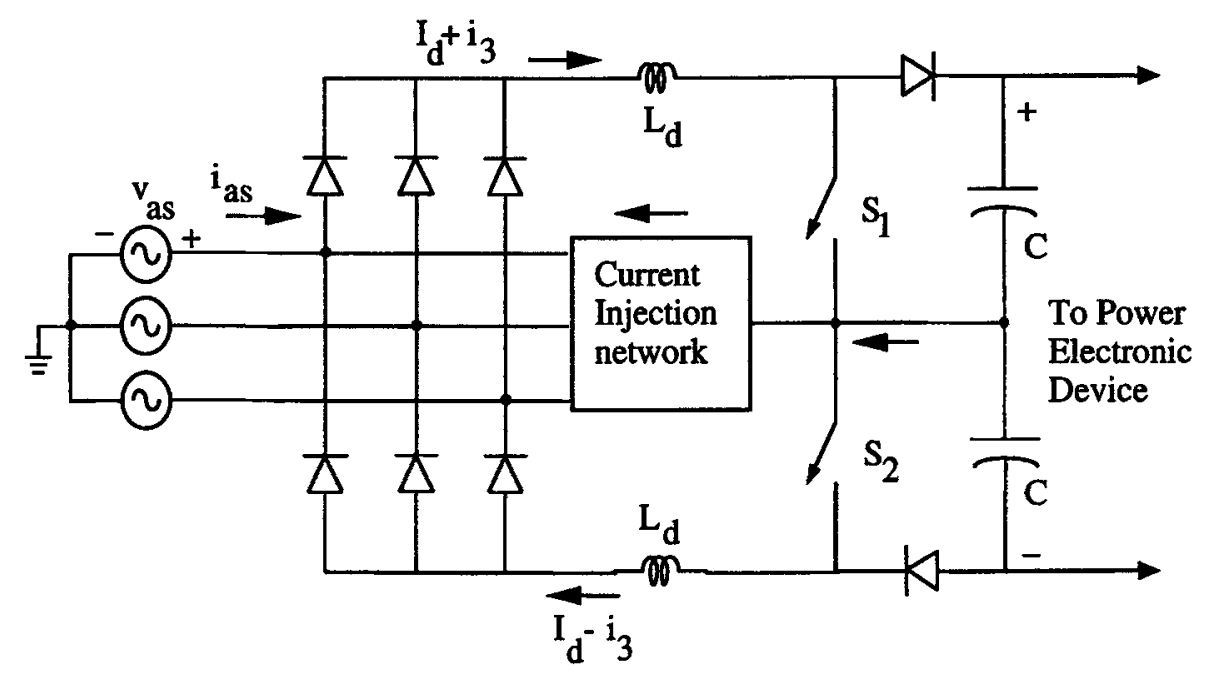

Figure 4. Current waveshaping technique for three-phase applications.

\subsection{Current waveshaping techniques}

In this section, some of the waveshaping techniques used for single and three-phase applications are reviewed. Figure 3 shows a typical current waveshaping technique for single phase loads.

The circuit is a boost converter drawing unity power factor current from the utility. The output DC voltage $V_{d}$ is regulated to a value which is higher than the peak of the utility voltage $v_{L L}$. In the boost converter approach, the input current $i_{s}$ is in phase with $v_{L L}$. The power electronics processor is then connected to this output. This method is extremely popular for single-phase applications. For three-phase applications, a current waveshaping technique is shown in figure 4 . This method is applicable where input transformer isolation is required for other reasons. In this method, a third harmonic current is injected through the current circulation network reducing the THD of the current drawn from the utility. The principle of operation, design and implementation are discussed by Naik (1993) and Rastogi (1993). The output voltage is regulated to be at a level higher than the peak of the 
input voltage. For those cases where input isolation is not required, a topology called the Vienna Rectifier may be used (Kolar \& Zach 1994). The method described by Kolar et al (1997) can be used for universal input three-phase voltages or where there are large input voltage variations.

\subsection{Passive filters}

Filters are a method of "cleaning" up the current waveforms drawn from the utility in cases where the load does not contain a waveshaping circuit. Active and passive filters are used either together (to form hybrid filters) or separately (to reduce current harmonics).

Passive filters can be connected either in parallel with the load (shunt filter) or in series with it (series filter). An ideal shunt filter serves as a short circuit for load harmonic currents. A series filter consists of an impedance connected in series with the utility and acts as an open circuit to load harmonic currents. The disadvantages with passive filters are as follows.

(1) They are bulky;

(2) the filter impedance can resonate with the AC system impedance, resulting in increased voltage distortion and damage to equipment;

(3) overcompensation of Vars can result in lowering the power factor.

These drawbacks of passive filters can be overcome by active filters.

\subsection{Active filters}

Active filters can also be connected in series and shunt mode. An example of an active filter for a three-phase, four-wire system (Quinn et al 1993) is shown in figure 5.

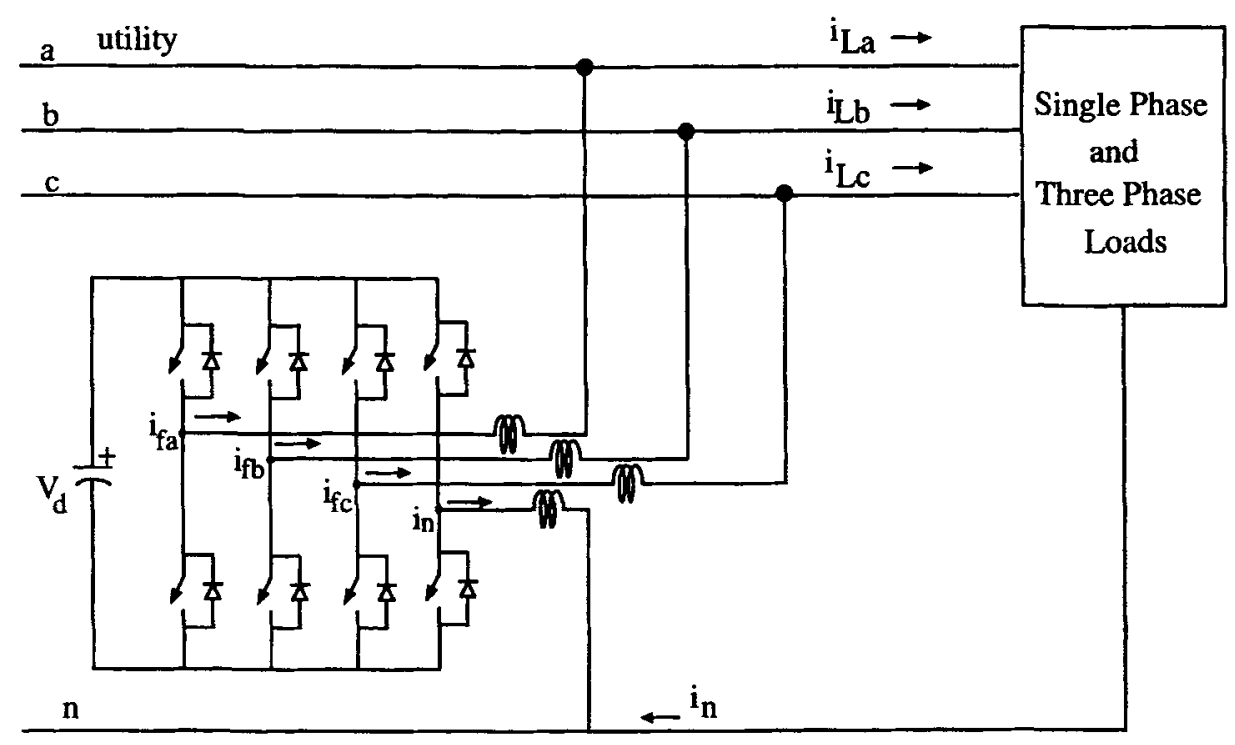

Figure 5. Four-legged inverter active filter for three-phase four-wire systems. 


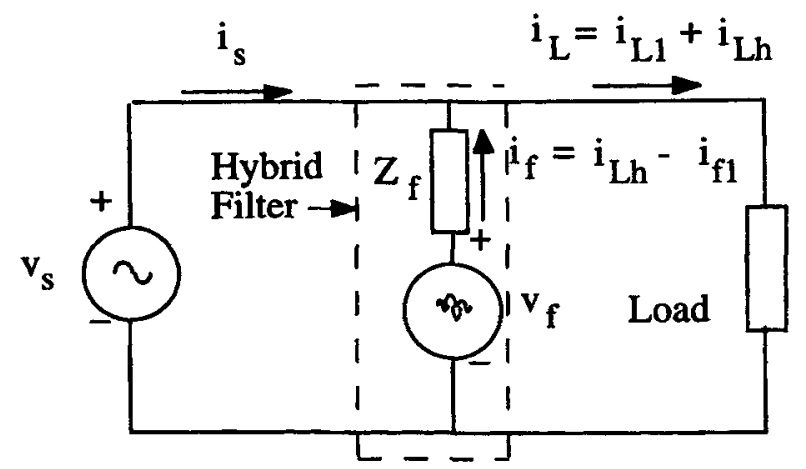

Equivalent circuit of a hybrid filter
Figure 6. Equivalent circuit of a hybrid filter.

Here, the four-legged converter (optionally through a line frequency transformer) is connected to the utility. The switch-mode converter neutralizes the load harmonic currents (in all phases, including the neutral), such that the utility supplies only the line-frequency currents. This topology is well suited at low and medium power levels where the required space needs to be minimized. The VA rating of the converter switches is very high. This scheme is not suitable at higher power levels (greater than $50 \mathrm{~kW}$ ) as operation of the converter at lower switching frequency leads to a lower current loop band-width and hence it is not possible to neutralize higher frequency current harmonics. Another concern is the EMI (electro-magnetic interference) produced by such an arrangement.

\subsection{Hybrid filters}

Hybrid filters combine the ruggedness of passive filters with the above mentioned advantages of active filters. Figure 6 is an example of a hybrid filter (Rastogi et al 1995). In this scheme, the active portion of the filter (shown as a voltage source $v_{f}$ ) is connected in series with a passive impedance $Z_{f} . Z_{f}$ is used to block the utility voltage by making $v_{f}$ draw a fundamental frequency current $i_{f 1}$ through it. This reduces the voltage rating and hence the $\mathrm{kVA}$ rating of $v_{f}$ substantially. However, the design of this filter is dependent on system parameters and knowledge of the load harmonic currents are required in order to design $Z_{f}$. Also, hybrid filters are not as compact as all active filters.

\subsection{All solid state per-phase solution for utility applications}

Often in utility-interactive applications at high power, the utility voltage is of the order of a few kilovolts, for example, $13.8 \mathrm{kV}$ or $34.5 \mathrm{kV}$. To meet the voltage requirement with devices of limited voltage ratings ( 3 to $4 \mathrm{kV}$ as with GTOs), the following options are available.

(1) A line frequency voltage matching transformer to translate the utility voltage level to a value at which the devices can operate. This is the simplest solution used almost always in the past. However, there are several problems associated with this approach. The line-frequency transformer is bulky and causes significant losses and, being a 


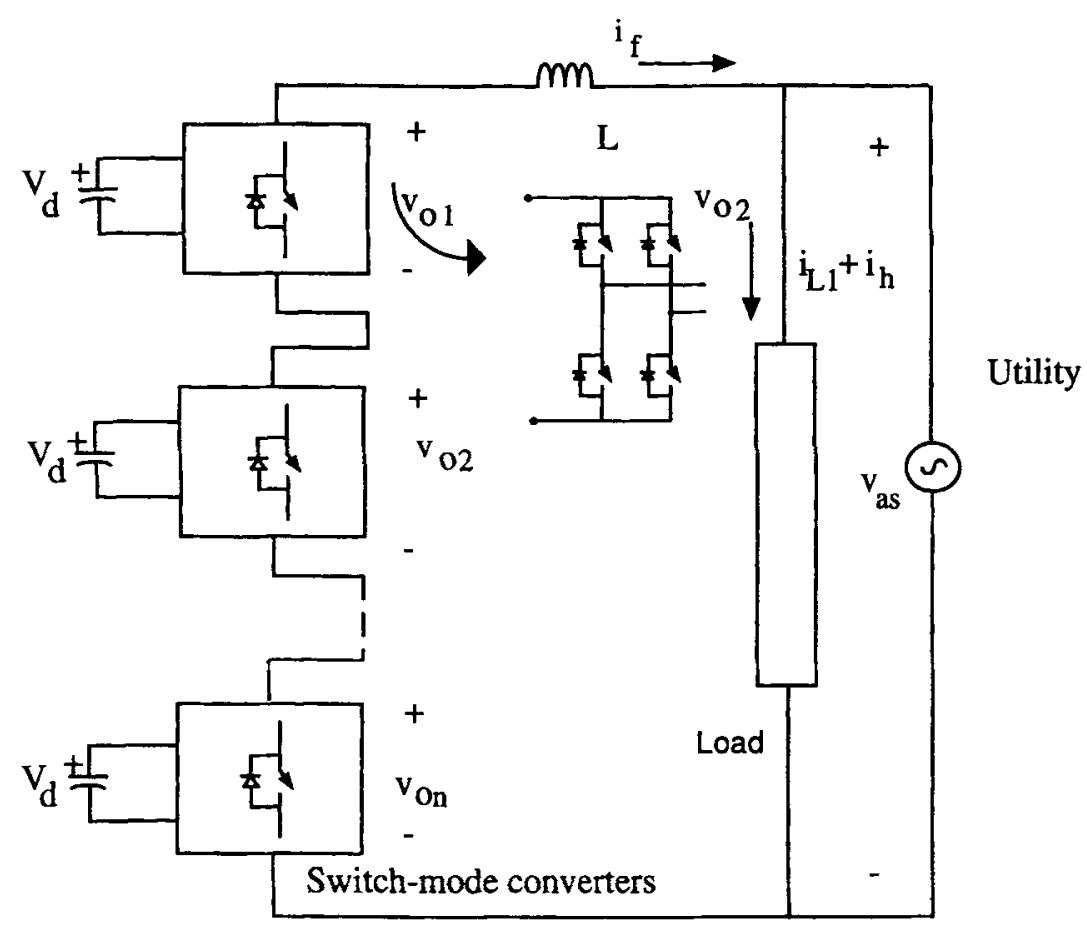

Figure 7. Schematic diagram of a hybrid all-switching series converter for utility applications.

mature technology, its cost is not expected to decline. The presence of a line-frequency transformer also results in the need for an additional DC demagnetizing current control loop to prevent the transformer from becoming saturated due to non-idealities in the main control loop and in the power circuit.

(2) Multi-level inverters are being considered (Baker 1980; Hochgraf et al 1994; Matsui 1995). However, for levels greater than three, the current flow in and out of the neutral point results in voltage variations of the neutral. This calls for additional neutral point voltage control (Fukuda \& Sagawa 1995; Matsui 1995) and a limitation in the switching frequency.

(3) The switches in the switch-mode converter may comprise of a series connection of discrete devices (e.g. GTOs). However the devices are derated and operate below their rated voltage rating (Takeda et al 1995; Ichikawa et al 1995).

A solution to the above problems, as shown in figure 7, is proposed by Paice \& Edwards (1987), Mohan \& Kamath (1995) and Peng et al (1995). It consists of a number of converters whose outputs are connected in series, on a per-phase basis. The arrangement has the following properties: It consists of a set of slow switching converters (switching at line frequency or its low multiple) whose outputs are connected in series with a fast-switching PWM converter. The DC bus voltages in these converters are independent of each other and may or may not be equal. The devices are matched to their switching requirements, for example large rating GTOs and IGBTs for the slow switching converters and fast switching IGBTs for the PWM switching converter. The function of the slow switching converter 
is to block the utility voltage, while that of the fast switching converter is to inject the appropriate current. Since the fast switching converter operates at low voltage and hence a low power, it produces much lower EMI (electro-magnetic interference) as compared to a single conventional converter operating at high power. There is also a decrease in the size of the interface inductor as compared to a single six-switch converter topology for the same current ripple and switching frequency.

Simulation and experimental results of a proof of concept prototype with three converters connected in series and tested for an active filter application are presented by Mohan \& Kamath (1997). With improvements in device technology, both in terms of performance and cost, and the use of digital control techniques to improve dynamic performance of the system, there is a trend towards using all-solid state solutions to power quality problems. This is consistent with the PEBB (power electronics building block) concept where the power switches are combined with their gate drives and associated control circuitry into a single module, for a variety of applications. There have been continuing advances in semiconductor technology resulting in improvements in device switching characteristics at higher voltages, especially with the emergence of $\mathrm{SiC}$ (silicon carbide) devices (Weitzel et al 1996). This also indicates that the trend will be towards solid-state solutions for power electronic applications in general and active filters in particular.

The desire for better quality power also means an increase in the complexity of the functions that will have to be performed by the active filters of the future. Akagi (1996) has proposed the concept of a general unified power quality conditioner which consists of a series active filter and a shunt active filter. This power conditioner, in addition to harmonic compensation, also takes care of voltage regulation, voltage flicker/imbalance compensation, negative sequence current compensation and electric resonance damping.

\section{Conclusions}

There has been an increase in the use of power electronic loads causing concern for power quality. This paper describes some of the methods that are currently being considered to address this issue.

\section{References}

Akagi H 1996 New trends in active filters for power conditioning. IEEE Trans. Ind. Appl. 32: $1312-1322$

Baker R 1980 High-voltage converter circuit. US Patent No. 4,203,151

Duffey C, Stratford R 1988 Update of harmonic standard IEEE 519: IEEE recommended practices and requirements for harmonic control in electric power systems. IEEE Ind. Appl. Soc. (PCIC) Conference

Fukuda S, Sagawa A 1995 Modeling and control of a neutral-point clamped voltage-source converter. IPEC-Yokohama 1995 Conference Records, vol. 1, pp 470-475

Hochgraf C, Lasseter R, Divan D, Lipo T 1994 Comparison of multi-level inverters for static var compensation. IEEE-Ind. Appl. Soc. Conference Records, pp 921-928 
Ichikawa F, Yajima M, Nakajima T, Irokowa S, Kawakami N 1995 Operating experience of a 50 MVA self-commutated SVC at the Shin-Shinano substation. IPEC-Yokohama 1995 Conference Records. vol. 1, pp 597-602

Kolar J, Zach F 1994 A novel three-phase utility interface minimizing line current harmonics of high-power telecommunications rectifier modules. IEEE ITEC Conference Proceedings, pp 367-374

Kolar J, Hari S, Drofenik V, Mohan N, Zach F 1997 A novel three-phase three-switch three-level high power factor SEPIC-type AC-to-DC Converter. IEEE APEC Conference Proceedings, pp 657-665

Matsui M 1995 Method for controlling neutral point for static var compensation. IPEC-Yokohama 1995 Conference Records, vol. 1, pp 488-493

Mohan N, Kamath G R 1995 A novel, per-phase interface of power electronic apparatus for power system applications. North American Power Symposium 1995 Proceedings, pp 457-461

Mohan N, Kamath G R 1997 A hybrid all-switching per-phase solution for power electronics utility application. IEEE IECON Conference Proceedings (to be published)

Naik R 1993 A novel sinusoidal-current, 3-phase utility interface: hardware implementation. M S thesis, University of Minnesota, Minneapolis

Paice D, Edwards C 1987 High voltage modular inverter and control system thereof. US patent No. 4674024

Peng F, Lai J, McKeenver J, Van Coevering J 1995 A multilevel voltage-source inverter with separate DC sources for static var generation. IEEE-Ind. Appl. Soc. Conference Records, pp 2541-2548

Quinn C, Mohan N, Mehta H 1993 A four-wire, current-controlled converter provides harmonic neutralization in three-phase, four wire systems. IEEE-APEC Conference Proceedings, pp 841-846

Rastogi M 1993 Analysis and optimization of a novel 3-phase, sinusoidal line current rectifier. M S thesis, University of Minnesota, Minneapolis

Rastogi M, Mohan N, Edris A 1995 Hybrid-active filtering of power system harmonics. IEEE Trans. Power Delivery 10: 1994-2000

Redl R, Tenti P, van Wyk J 1997 Combatting the pollution of the power distribution systems by electronic equipment. IEEE Appl. Power Electron. Conf. Exposition, pp 42-48

Takeda M, Murukami S, lizuka A, Hirakawa M, Kishida M, Hase S, Mochinaga H 1995 Development of an SVG series for voltage control over three-phase unbalance caused by railway load. IPEC-Yokohama 1995 Conference Records. vol. 1, pp 603-608

Weitzel C, Palmour J, Carter C, Moore K. Nordquist K, Allen S, Thero C, Bhatnagar M 1996 Silicon carbide high-power devices. IEEE Trans. Electron. Devices 43: 1732-1739 